\title{
Numb downregulation suppresses cell growth and is associated with a poor prognosis of human hepatocellular carcinoma
}

\author{
CHENGZHI XIE ${ }^{1,2^{*}}$, ZHENHUI LU $^{3 *}$, GUOXING LIU $^{1}$, YU FANG $^{1}$, JIEFENG LIU $^{1}$, ZHAO HUANG $^{1}$, \\ FUSHENG WANG $^{1}$, XIAOLONG WU ${ }^{1}$, XIAOHUA LEI ${ }^{1}$, XIAOCHENG LI ${ }^{1}$, YUEMING ZHANG ${ }^{1}$, \\ ZECHENG HU ${ }^{1}, \mathrm{KE} \mathrm{QIAN}^{1}$, JIXIONG HU ${ }^{1}$, SHENGFU HUANG ${ }^{1}$, DEWU ZHONG ${ }^{1}$ and XUNDI XU ${ }^{1}$ \\ ${ }^{1}$ Division of Hepatobiliary-Pancreatic Surgery, Department of Surgery, The Second Xiangya Hospital, \\ Central South University, Changsha, Hunan 410011; ${ }^{2}$ Department of General Surgery, The Second Affiliated Hospital, \\ Hunan University of Chinese Medicine, Changsha, Hunan 410005; ${ }^{3}$ Department of Hepatobiliary Surgery, General Hospital \\ of Ningxia Medical University, Yinchuan, Ningxia Hui Autonomous Region 750004, P.R. China
}

Received February 21, 2015; Accepted June 24, 2015

DOI: $10.3892 / \mathrm{ijmm} .2015 .2279$

\begin{abstract}
Numb, an endocytic adaptor, is a known cell fate determinant that participates in asymmetric cell division. The present study aimed to explore the potential roles of $\mathrm{Numb}$ in hepatocarcinogenesis. Numb expression was investigated in hepatocellular carcinomas (HCC) with reverse transcription-quantitative polymerase chain reaction and immunohistochemical examination; its association with the prognosis of HCC patients was analyzed. In addition, the effects of Numb deletion on proliferation of HCC cells and its relevant molecules were evaluated in Huh7 and HepG2 cells. Numb overexpression was observed in $62 \%$ of adjacent non-tumor tissues and $46 \%$ of tumor tissues. Overexpression of Numb in HCC was associated with histological grade, portal vein invasion and the number of tumors $(\mathrm{P}=0.001,0.022$ and 0.034 respectively). Multivariate analysis revealed that $N u m b$ expression was an independent prognostic indicator of HCC patients. Methylation of the Numb promoter contributed to hepatocarcinogenesis. In vitro assays demonstrated that $N u m b$ silencing resulted in inhibition of cell proliferation, induction of apoptosis, downregulation of cyclin-dependent protein kinase 4 (CDK4) and
\end{abstract}

Correspondence to: Professor Xundi Xu, Division of Hepatobiliary-Pancreatic Surgery, Department of Surgery, The Second Xiangya Hospital, Central South University, 139 Renmin Zhong Road, Changsha, Hunan 410011, P.R. China

E-mail: xuxundi@126.com

*Contributed equally

Abbreviations: HCC, hepatocellular carcinoma; BAK, Bcl-2 homologous antagonist/killer; CDK4, cyclin-dependent protein kinase 4; SKP2, S-phase kinase-associated protein 2; p21, cyclin-dependent kinase inhibitor 1; MSP, methylation-specific polymerase chain reaction

Key words: hepatocellular carcinoma, Numb, proliferation, prognosis, apoptosis
S-phase kinase-associated protein 2 (SKP2), and upregulation of Bcl-2 homologous antagonist/killer (BAK) and cyclin-dependent kinase inhibitor 1 (p21). The present study suggests that downregulation of Numb inhibits colony formation and cell proliferation, induces apoptosis of HCC cells and independently predicts the poor prognosis of HCC patients. Thus, Numb has a potential role in the development and progression of HCC.

\section{Introduction}

Primary liver cancer, which consists predominantly of hepatocellular carcinoma (HCC), is the sixth most common cancer worldwide and the second most common cause of cancer mortality (1). HCC accounts for 70 to $90 \%$ of primary liver cancers. There is an increasing understanding of the molecular mechanisms that induce hepatocarcinogenesis, including abrogation of cell-cycle checkpoints, and activation of oncogenic pathways and Notch (2-4). Further detailed clarification of the molecular pathways involved in hepatocarcinogenesis could improve the treatment of HCC patients.

Numb, a membrane-associated protein, asymmetrically localizes during the division of neuroblasts and subsequently segregates to one daughter cell at telophase, where it functions as an intrinsic determinant of cell fate (5-7). Drosophila and vertebrate $N u m b$ genes have a role in binary cell fate decision in the peripheral and central nervous system (8-9). Intrinsically inherited Numb interacts with the cell surface receptor Notch and a serine-threonine kinase, $N u m b$-associated kinase (Nak), and functions, at least in part, by antagonizing Notch activity (10-11). Subversion of Numb is associated with important human pathologies, including cancer. An in vivo RNA interference screen in a model of mouse lymphomagenesis identified $N u m b$ as a putative tumor suppressor, whose ablation can accelerate the onset of lymphomas (12). In breast cancer there is a frequent loss of Numb expression, which causes increased activity of the receptor Notch (13). Furthermore, Numb enters in a tricomplex with p53 and the E3 ubiquitin ligase, HDM2, thereby preventing ubiquitination and degradation of p53, and results in increased p53 protein levels and 
activity (14). The present study was designed to assess the role of Numb in liver carcinogenesis.

\section{Materials and methods}

Patients and follow-up. Fresh tumor samples and corresponding non-tumor tissues used in reverse transcription quantitative-polymerase chain reaction (RT-qPCR) and western blot analyses were randomly collected from HCC patients who underwent curative resection between 2006 and 2009 in The Second Xiangya Hospital (Central South University, Hunan, China). All the specimens were removed and preserved as described (15). Tumor specimens used in immunohistochemistry were obtained from $85 \mathrm{HCC}$ patients (62 males and 23 females, 28-72 years of age) who underwent hepatectomy in the department. All these patients had hepatitis B virus infection. The median follow-up period of these patients was 34 months (range, 1-78 months). Previous informed consent was obtained, and the study protocol was approved by the Ethics Committee of The Second Xiangya Hospital.

Cell lines. Huh7 and HepG2 cell lines were purchased from the certified biological resources center China Center for Type Culture Collection (Wuhan, China). These cell lines were maintained at $37^{\circ} \mathrm{C}$ in a humidified incubator under $5 \% \mathrm{CO}_{2}$ conditions, as described previously $(2,16)$.

Immunohistochemistry. A total of 85 samples of HCC and their corresponding non-tumoral liver tissue were assessed by immunohistochemistry. Immunostaining was performed as described previously (17). Polyclonal rabbit anti-human Numb (sc-25668, 1:100 dilution; Santa Cruz Biotechnology, Inc., Dallas, TX, USA) was used to detect the expression of Numb.

Methylation-specific PCR (MSP), RT-qPCR and western blot analyses. RT-qPCR of 13 HCC samples and related non-tumor counterparts were analyzed as described previously (17). The primers are exhibited in Table I. For other analyses, RNA was collected from cultured cells with the TRIzol reagent (Invitrogen Life Technologies, Carlsbad, CA, USA), according to the manufacturer's instructions.

Nine HCC samples and the related non-tumor-counterparts were further used in western blot analysis as described previously (15). The following primary antibodies were used in western blot analysis: Rabbit polyclonal antibodies against Numb, cyclin-dependent protein kinase 4 (CDK4) (sc-260), S-phase kinase-associated protein 2 (SKP2) (sc-7164), Bcl-2 homologous antagonist/killer (BAK) (sc-832), cyclin-dependent kinase inhibitor 1 (p21) (sc-397) and GAPDH (sc-25778) (all from Santa Cruz Biotechnology, Inc.).

Thirty primary HCC tumors and their paired non-tumorous tissues were investigated by MSP, as described previously (18).

Cell proliferation, colony formation, cell cycle and apoptosis assay. The functional role of Numb in HCC cells was analyzed with small interfering RNA (siRNA). The Numb siRNA sequence was UGGAACAUAAACAUCCUUCUUUCUC. The negative control siRNA (cat. no. 12935-200; Invitrogen Life Technologies) was used as the negative control for all the
Table I. DNA sequences of the primers used in the study.

\begin{tabular}{|c|c|}
\hline Primer name & Sequence $5^{\prime} \rightarrow 3^{\prime}$ \\
\hline \multicolumn{2}{|l|}{ RT-qPCR } \\
\hline$\beta$-actin-F & ATCATGTTTGAGACCTTCAACA \\
\hline$\beta$-actin-R & CATCTCTTGCTCGAAGTCCA \\
\hline Numb-F & GGCATACAGAGGTTCCTACA \\
\hline Numb-R & TGCTCCTTTGACCGCTAC \\
\hline$B A K-\mathrm{F}$ & CAGGGCTTAGGACTTGGTTT \\
\hline$B A K-\mathrm{R}$ & TTTTTTCAGGGTGAGGGGAT \\
\hline$S K P 2-\mathrm{F}$ & CTTTCTGGGTGTTCTGGATT \\
\hline$S K P 2-\mathrm{R}$ & GGAGCAATTAATCTGTAGATGAGG \\
\hline$p 21-\mathrm{F}$ & GCAGCGGAACAAGGAGT \\
\hline$p 21-\mathrm{R}$ & GGAGAAACGGGAACCAG \\
\hline$C D K 4-\mathrm{F}$ & CCCGAAGTTCTTCTGCAGTC \\
\hline$C D K 4-\mathrm{R}$ & GTCGGCTTCAGATTTCCAC \\
\hline \multicolumn{2}{|l|}{ MSP } \\
\hline Numb MSPm-F & TTTCGAAAGTGTTGGGATTATATAC \\
\hline Numb MSPm-R & AACTACAATAAACCAAAATCGCG \\
\hline Numb MSPu-F & TTGAAAGTGTTGGGATTATATATGT \\
\hline Numb MSPu-R & AACTACAATAAACCAAAATCACACC \\
\hline
\end{tabular}

RT-qPCR, reverse transcription-quantitative polymerase chain reaction; F, forward; R, reverse; MSP, methylation-specific PCR; $C D K 4$, cyclin-dependent protein kinase 4; $S K P 2$, S-phase kinase-associated protein 2; $\mathrm{Bak}, \mathrm{Bcl}-2$ homologous antagonist/killer; $p 21$, cyclindependent kinase inhibitor 1.

experiments. The transfection of siRNA into HepG2 and Huh7 was performed with Lipofectamine 2000 (cat. no. 11668-019; Invitrogen Life Technologies) according to the manufacturer's instructions.

Cell proliferation, colony formation, cell cycle and apoptosis assays were performed as described previously (16).

Statistical analysis. Statistical analyses were performed with SPSS 16.0 for Windows (SPSS, Inc., Chicago, IL, USA). Cumulative survival time was calculated by the Kaplan-Meier method and analyzed by the log-rank test. Univariate and multivariate analyses were based on the Cox proportional hazards regression model. The $\chi^{2}$ test, Fisher's exact test and Student's t-test were used for comparison between groups. All the tests were two-tailed. Values of $\mathrm{P}<0.05$ were considered to indicate a statistically significant difference.

\section{Results}

Numb expression in HCC. Cellular localization of the Numb protein was assessed by immunohistochemistry in the tumor tissue and their corresponding non-tumoral liver tissue from 85 samples of HCC. In general, high expression of the Numb protein was observed in both tumor tissue $(39 / 85,46 \%)$ and non-tumoral liver tissue $(53 / 85,62 \%)$, and the staining intensity varied widely. In normal liver and chronic hepatitis samples, Numb expression was low (Fig. 1A-a). The majority of cirrhotic liver samples showed increased $N u m b$ expression, particularly in 
A
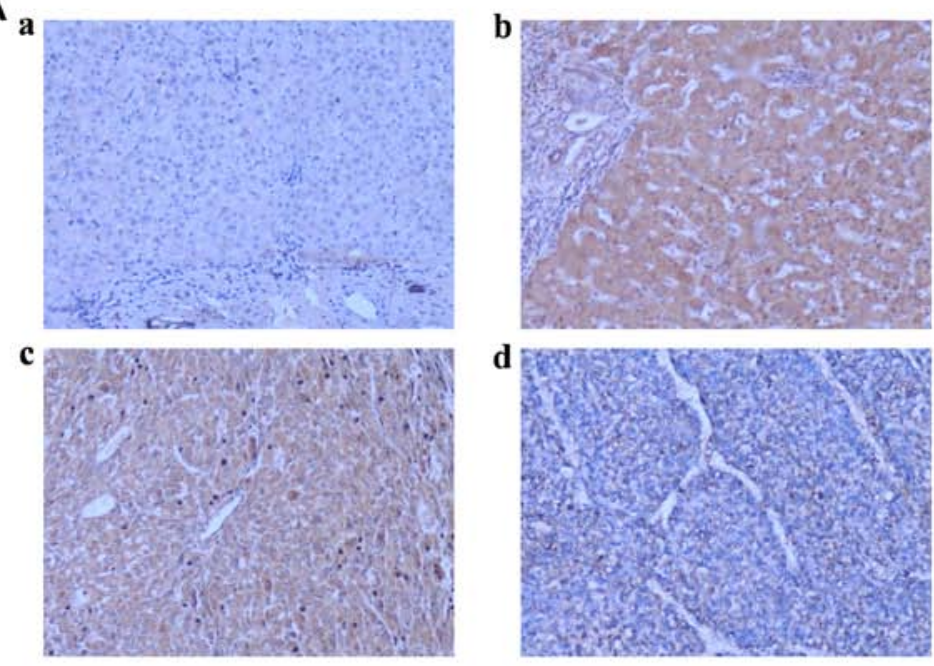

C

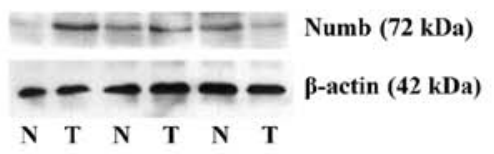

B

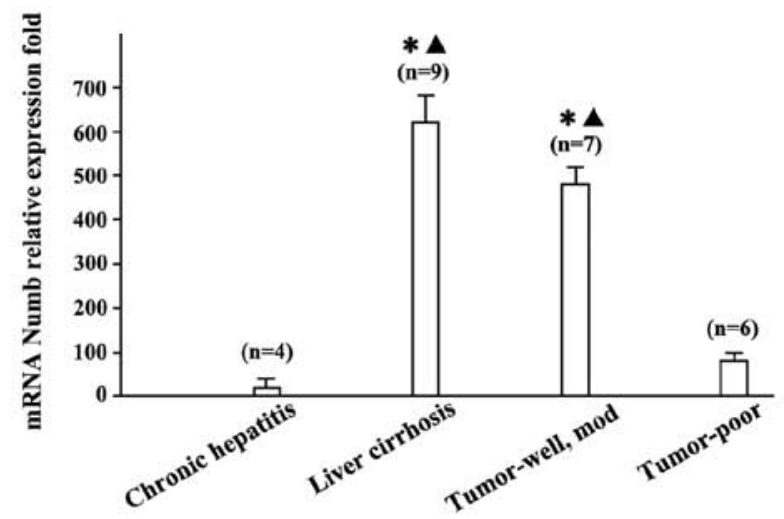

$\mathrm{E}$
D

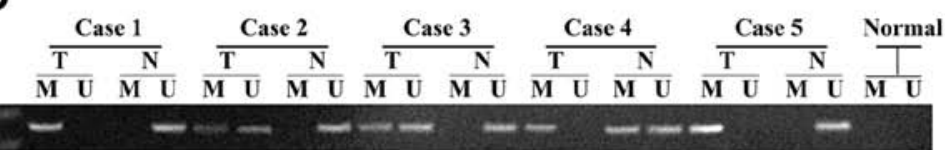

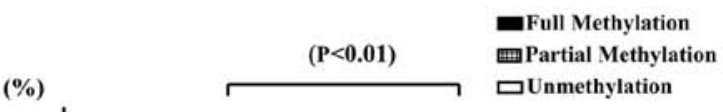

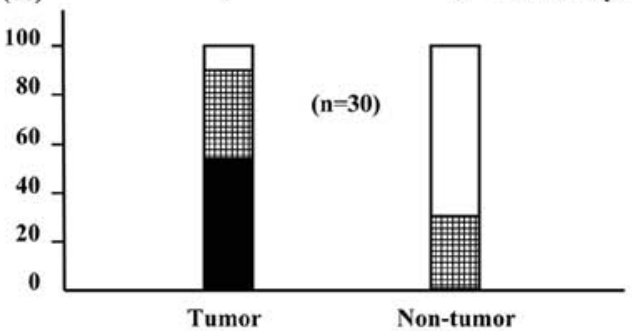

Figure 1. Expression of Numb in samples from hepatocellular carcinomas (HCC) patients. (A) Expression of Numb in non-tumorous and tumor liver tissues detected by immunohistochemistry; (a) chronic hepatitis, (b) liver cirrhosis, (c) moderately differentiated HCC, (d) poorly differentiated HCC. Magnification, x100. (B) Reverse transcription-quantitative polymerase chain reaction (PCR) was used to examine Numb mRNA expression from 13 paired HCC tissues and their non-tumor counterparts. The results (mean \pm standard deviation) were normalised for $\beta$-actin expression. Statistical analysis was performed comparing liver cirrhosis, well- and moderately differentiated tumors, and poorly differentiated tumors with chronic hepatitis; $\mathrm{P}<0.05$; and liver cirrhosis, and well-and moderately differentiated tumors compared with poorly differentiated tumors; ${ }^{\wedge} \mathrm{P}<0.05$. (C) The representative expression of Numb as assessed by western blot analysis. Lane 1, chronic hepatitis B; lanes 2 and 4, moderately differentiated tumors; lanes 3 and 5, liver cirrhosis; lane 6, poorly differentiated tumor. (D) Methylation of $N u m b$ promoter in HCC tissues was determined by methylation-specific PCR (MSP). (E) MSP showed that the methylation of Numb was significantly detected in HCC tissues (T) compared with the corresponding non-tumorous tissues $(\mathrm{N}) ; \mathrm{n}=19, \mathrm{P}<0.01$. M, methylated DNA; U, unmethylated DNA.

regenerative nodules (Fig. 1A-b). High expression of the Numb protein was significantly more frequent in the samples of cirrhotic liver $(49 / 58,84 \%)$ compared with the normal liver $(0 / 3,0 \%)$, chronic hepatitis $(4 / 24,17 \%)$ and cancer tissues $(39 / 85,46 \%)$, as shown in Table II. In the cancer tissues, the histopathological type of HCC was associated with Numb expression; the expression level decreased with poor cell differentiation. The majority of well- and moderately differentiated HCCs showed high Numb expression (36/46, 78\%) (Fig. 1A-c), while poorly differentiated HCCs showed a low Numb expression $(36 / 39,92 \%)$ (Table III; Fig. 1A-d). The high expression of Numb was more frequent in liver cirrhosis and well-differentiated HCCs compared with the normal liver, chronic hepatitis or poorly differentiated HCCs.

RT-qPCR analysis was performed by 13 paired non-tumor and tumor mRNA extracts. Numb mRNA expression levels in the tissues of liver cirrhosis $(n=9)$, well- and moderately differentiated $(n=7)$ and poorly differentiated liver tumors $(n=6)$ had 41-, 38- and 2-fold increased expression with respect to chronic hepatitis $(\mathrm{n}=4)(\mathrm{P}<0.05$ respectively). Additionally, decreased expression levels were observed in poorly differentiated liver tumors compared with those in the tissues of liver cirrhosis, and well- and moderately differentiated liver tumors $(\mathrm{P}<0.05$ respectively) (Fig. 1B). In addition, overexpression of Numb was further confirmed by a western blot analysis in 6 cases (Fig. 1C).

Aberrant methylation of Numb in HCC. The methylation frequency of $N u m b$ was investigated in 30 primary HCC tumors and their paired non-tumorous tissues by MSP (Fig. 1D).

In the tumor tissues, fully, partially or un-methylated alleles of $N u m b$ were detected in 16/30 (53.3\%), 11/30 (36.7\%) and 3/30 $(10 \%)$ cases, respectively, whereas in the paired non-tumorous tissues, $0 / 30(0 \%), 9 / 30(30 \%)$ and 21/30 (70\%) cases were identified correspondingly, which supported that methylation of Numb has a role in hepatocarcinogenesis (Fig. 1E).

Numb expression and its association with clinicopathological features and prognosis of the HCC patients. As shown in Table III, Numb expression in tumor samples was significantly associated with histological grade $(\mathrm{P}=0.001)$, portal vein invasion $(\mathrm{P}=0.022)$ and number of tumors $(\mathrm{P}=0.034)$ in the HCC patients. However, no statistically significant association was identified between $N u m b$ expression and the other clinical characteristics. 
Table II. Immunohistochemical analysis of Numb in cancer and non-cancer liver tissues.

\begin{tabular}{lrcr}
\hline & & \multicolumn{2}{c}{$\begin{array}{c}\text { Staining intensity } \\
\text { for Numb, no. }\end{array}$} \\
\cline { 3 - 4 } Pathological category & No. & Low & High \\
\hline Normal liver & 3 & 3 & 0 \\
Chronic hepatitis & 24 & 20 & 4 \\
Cirrhosis & 58 & $9^{\text {a,b }}$ & 49 \\
HCC & 85 & $46^{c}$ & 39
\end{tabular}

Intensity of Numb staining varied significantly according to liver disease state. ${ }^{\mathrm{a} C}$ Comparison with normal liver $(\mathrm{P}=0.007)$; ${ }^{\mathrm{b}}$ with chronic hepatitis $(\mathrm{P}<0.001)$; and ${ }^{\mathrm{c}}$ with cirrhosis $(\mathrm{P}<0.001)$. HCC, hepatocellular carcinomas.
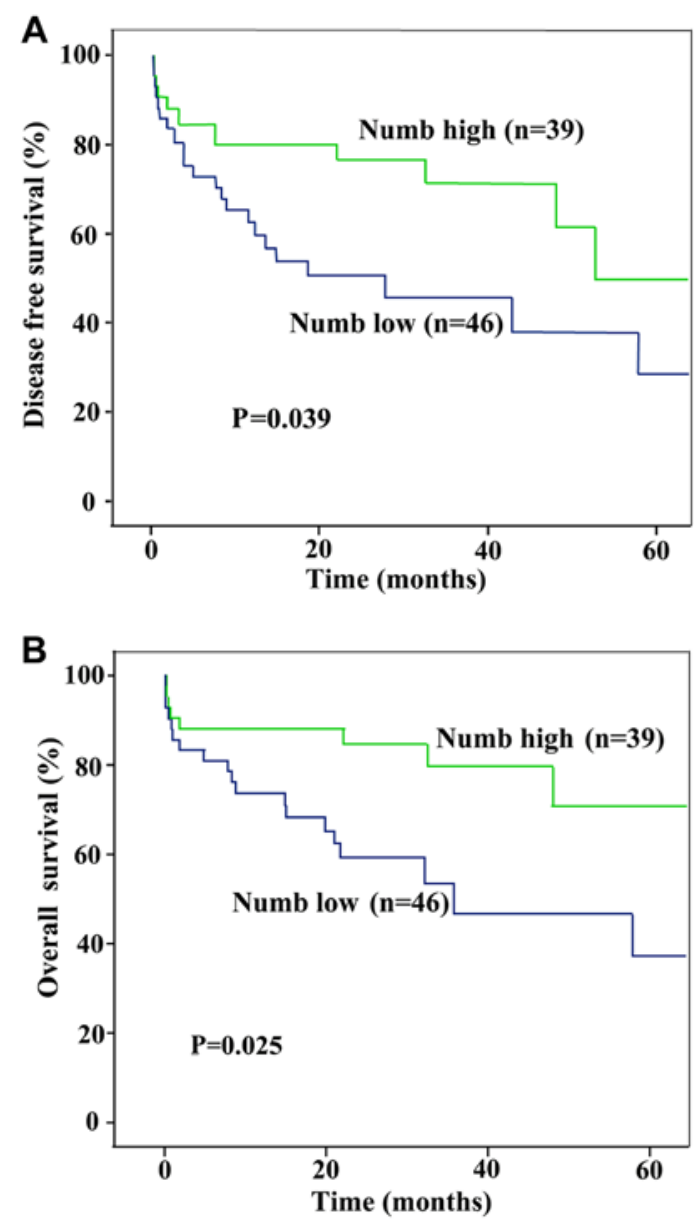

Figure 2. Kaplan-Meier analysis of disease-free and overall survival in 85 cases based on Numb expression. Compared with the group with low Numb expression, (A) the disease-free and (B) overall survival were significantly higher in the group with high Numb expression.

To further evaluate the prognostic value of Numb for HCC patients, univariate and multivariate analyses were performed for the clinicopathological characteristics and expression of Numb. In the univariate analysis, tumor differentiation, portal vein involvement and number of tumors were revealed to be associated with disease-free and overall survival of the
Table III. Association between Numb expression and clinicopathological parameters in HCC.

\begin{tabular}{lrrrr}
\hline & & \multicolumn{2}{c}{$\begin{array}{c}\text { Expression } \\
\text { of Numb, } \mathrm{n}\end{array}$} & \\
\cline { 3 - 4 } Parameter & $\mathrm{n}$ & Low & High & P-value \\
\hline Age, years & & & & \\
$\geq 60$ & 55 & 24 & 21 & \\
$<60$ & 30 & 22 & 8 & NS \\
Gender & & & & \\
$\quad$ Male & 62 & 36 & 26 & \\
Female & 23 & 10 & 13 & NS \\
Tumor size, cm & & & & \\
$\quad<5$ & 12 & 4 & 8 & \\
$\geq 5$ & 73 & 42 & 31 & NS \\
Histological grade & & & & \\
$\quad$ Well/moderately differentiated & 46 & 10 & 36 & \\
Poorly/undifferentiated & 39 & 36 & 3 & 0.001 \\
Portal vein invasion & & & & \\
$\quad$ Yes & 24 & 16 & 8 & \\
$\quad$ No & 61 & 30 & 31 & 0.022 \\
$\quad$ No. of tumors & & & & \\
$\quad$ Solitary & 58 & 31 & 27 & \\
$\quad$ Multiple & 27 & 15 & 12 & 0.034 \\
Capsular formation & & & & \\
$\quad$ Yes & 36 & 21 & 15 & \\
$\quad$ No & 49 & 25 & 24 & NS \\
\hline & & & &
\end{tabular}

Patients with hepatocellular carcinomas (HCC) were divided into Numb 'high' group (final density was higher compared with the median) and 'low' group (final density was lower compared with the median). The patient and disease profiles in each group were compared. NS, not significant between any groups.

HCC patients. No significant prognostic significance was identified in the other characteristics, including gender, age and capsular formation of patients for overall or disease-free survival (Table IV).

Individual features that showed significance by univariate analysis were adopted as covariates in a multivariate Cox proportional hazards model and subsequently the combined variables were further analyzed. Numb was shown to be an independent prognostic indicator for disease-free $(\mathrm{P}=0.039)$ and overall survival $(\mathrm{P}=0.025)$ (Fig. $2 \mathrm{~A}$ and $\mathrm{B}$ ).

Antiproliferation of HCC cells by Numb silencing. Tumor suppression was assessed by soft agar formation and cell growth assay.

The soft agar assay showed that the frequency of colony formation of Huh7 cells was significantly inhibited (238.67 \pm 24.97 vs. $35.00 \pm 3.64, \mathrm{P}<0.01)$ in Numb silencing compared with scramble cells (Fig. 3A).

Numb silencing also significantly inhibited the cell growth of Huh7 and HepG2 cells by the MTT assay. The statistical 
Table IV. Univariate and multivariate analyses of factors associated with survival rate and recurrence.

\begin{tabular}{|c|c|c|c|c|c|c|}
\hline \multirow[b]{3}{*}{ Factors } & \multicolumn{3}{|c|}{ Overall survival } & \multicolumn{3}{|c|}{ Cumulative recurrence } \\
\hline & \multirow{2}{*}{$\begin{array}{c}\text { Univariate } \\
\text { P-value }\end{array}$} & \multicolumn{2}{|c|}{ Multivariate } & \multirow{2}{*}{$\begin{array}{c}\text { Univariate } \\
\text { P-value }\end{array}$} & \multicolumn{2}{|c|}{ Multivariate } \\
\hline & & HR (95\% CI) & P-value & & HR $(95 \%$ CI) & P-value \\
\hline \multicolumn{7}{|l|}{ Age, years } \\
\hline $\begin{array}{l}<65 \\
\geq 65\end{array}$ & 0.646 & $\begin{array}{c}0.694 \\
(0.349-2.753)\end{array}$ & 0.376 & 0.971 & $\begin{array}{c}0.866 \\
(0.378-1.981)\end{array}$ & 0.733 \\
\hline \multicolumn{7}{|l|}{ Gender } \\
\hline $\begin{array}{l}\text { Male } \\
\text { Female }\end{array}$ & 0.504 & $\begin{array}{c}0.980 \\
(0.340-2.647)\end{array}$ & 0.970 & 0.607 & $\begin{array}{c}0.979 \\
(0.346-2.772)\end{array}$ & 0.968 \\
\hline \multicolumn{7}{|c|}{ Numb expression } \\
\hline $\begin{array}{l}\text { Low } \\
\text { High }\end{array}$ & $<0.001$ & $\begin{array}{c}9.303 \\
(2.812-30.779)\end{array}$ & $<0.001$ & $<0.001$ & $\begin{array}{c}13.600 \\
(3.695-50.056)\end{array}$ & $<0.001$ \\
\hline \multicolumn{7}{|c|}{ Tumor size, $\mathrm{cm}$} \\
\hline $\begin{array}{l}<3 \\
\geq 3\end{array}$ & 0.681 & $\begin{array}{c}0.925 \\
(0.396-2.157)\end{array}$ & 0.598 & 0.856 & $\begin{array}{c}0.950 \\
(0.405-2.226)\end{array}$ & 0.906 \\
\hline \multicolumn{7}{|c|}{ Tumor differentiation } \\
\hline $\begin{array}{l}\mathrm{I} / \mathrm{II} \\
\mathrm{III} / \mathrm{IV}\end{array}$ & $<0.001$ & $\begin{array}{c}0.349 \\
(0.151-0.803)\end{array}$ & 0.013 & $<0.001$ & $\begin{array}{c}0.332 \\
(0.144-0.762)\end{array}$ & 0.009 \\
\hline $\begin{array}{c}\text { Tumor nun } \\
\text { Solitary } \\
\text { Multiple }\end{array}$ & 0.001 & $\begin{array}{c}0.565 \\
(0.232-1.373)\end{array}$ & 0.207 & 0.010 & $\begin{array}{c}0.848 \\
(0.345-2.084)\end{array}$ & 0.719 \\
\hline $\begin{array}{l}\text { Portal vein } \\
\text { No } \\
\text { Yes }\end{array}$ & $<0.001$ & $\begin{array}{c}0.403 \\
(0.168-0.964)\end{array}$ & 0.041 & $<0.001$ & $\begin{array}{c}0.271 \\
(0.110-0.671)\end{array}$ & 0.005 \\
\hline $\begin{array}{l}\text { Tumor enc } \\
\text { No } \\
\text { Yes }\end{array}$ & 0.369 & $\begin{array}{c}1.282 \\
(0.521-3.156)\end{array}$ & 0.588 & 0.747 & $\begin{array}{c}0.910 \\
(0.359-2.311)\end{array}$ & 0.844 \\
\hline
\end{tabular}

HR, hazard ratio; CI, confidence interval.

significance $(\mathrm{P}<0.01)$ between cultures treated with $N u m b$ siRNA versus scramble is shown in Fig. 3B.

Induction of apoptosis by ectopic expression of Numb. To explore the molecular mechanism of Numb in HCC development, the role of Numb in the cell cycle was investigated with flow cytometry. In the Huh7 cells tested, treatment with Numb siRNA for $24 \mathrm{~h}$ increased the $\mathrm{G}_{0}-\mathrm{G}_{1}$ phase fraction and decreased the $\mathrm{S}$ phase fraction when compared with the scramble-treated cultures. A representative result is shown in Fig. 3C with the following fraction values for cultures treated with $N u m b$ siRNA versus scramble $\left(\mathrm{G}_{0}-\mathrm{G}_{1}: 54.35\right.$ vs. $48.91 ; \mathrm{S}$ phase fraction: 31.22 vs. $35.87 ; \mathrm{G}_{2}-\mathrm{M}$ : 14.44 vs. 15.22 , respectively).

The apoptotic index was compared between $N u m b$ siRNA and scramble cells by TUNEL staining. The TUNEL assay revealed that apoptotic cells treated by Numb siRNA were significantly higher compared with those of the scramble control (48 h: 4.39 vs. $21.94 \%$; 72 h: 4.47 vs. $36.10 \%$, respectively, $\mathrm{P}<0.001$; Fig. 3D).

To further elucidate the molecular basis of cell cycle and apoptosis induced by Numb silencing, the relevant molecules were screened by RT-qPCR and confirmed by western blot analysis. RT-qPCR analysis revealed that $C D K 4$ and $S K P 2$ were downregulated whereas $B A K$ and $p 21$ were upregulated in the Huh7 cell line following Numb siRNA treatment $(\mathrm{P}<0.05$, respectively) (Fig. 4A). Western blot analysis further confirmed these results (Fig. 4B).

\section{Discussion}

In the present study, Numb was overexpressed in patients with HCC. A decreased expression of Numb in human HCC was an independent predictor of poor prognosis. Numb ablation by siRNA in vitro could inhibit tumor cell proliferation by downregulating $C D K 4$ and $S K P 2$ and upregulating p21 expression, and enhancing the apoptotic potential by upregulating $B A K$.

The present results showed that the Numb gene was involved in hepatocarcinogenesis and its decreased expression was associated with a poor prognosis of HCC patients. In the non-tumor liver tissue, Numb was overexpressed in the majority of cirrhotic nodules and liver tissue infected 
A
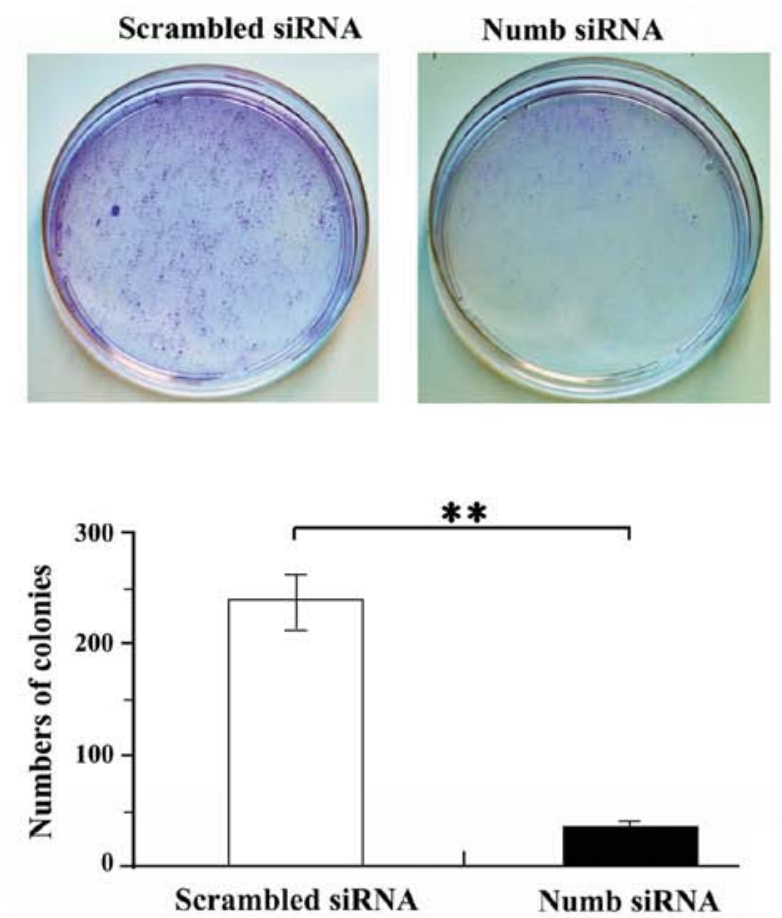

C
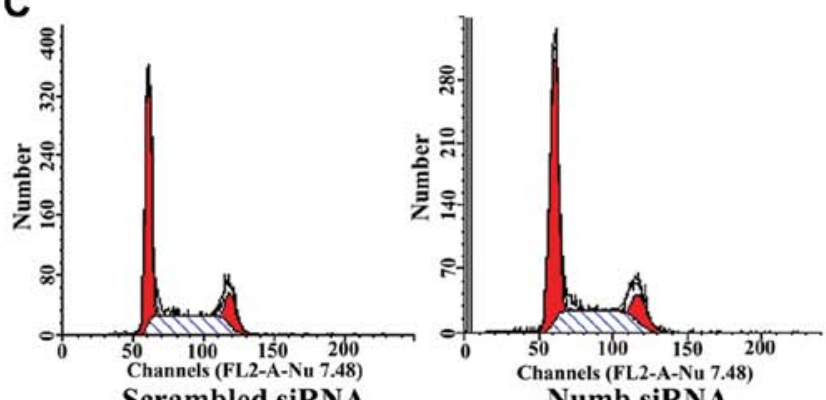

Numb siRNA

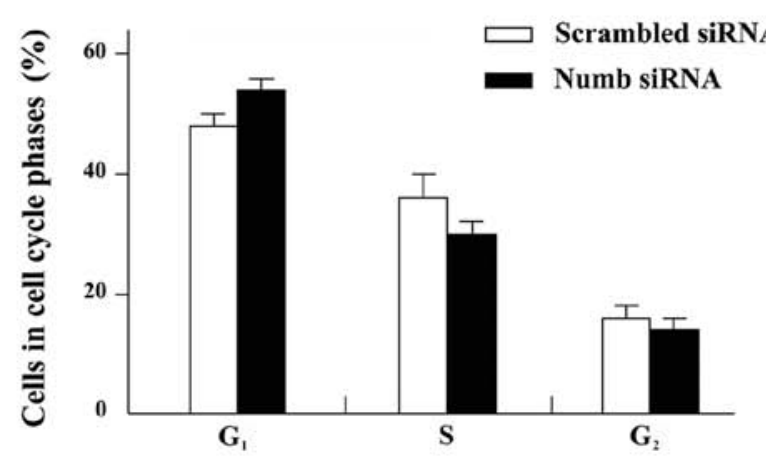

B
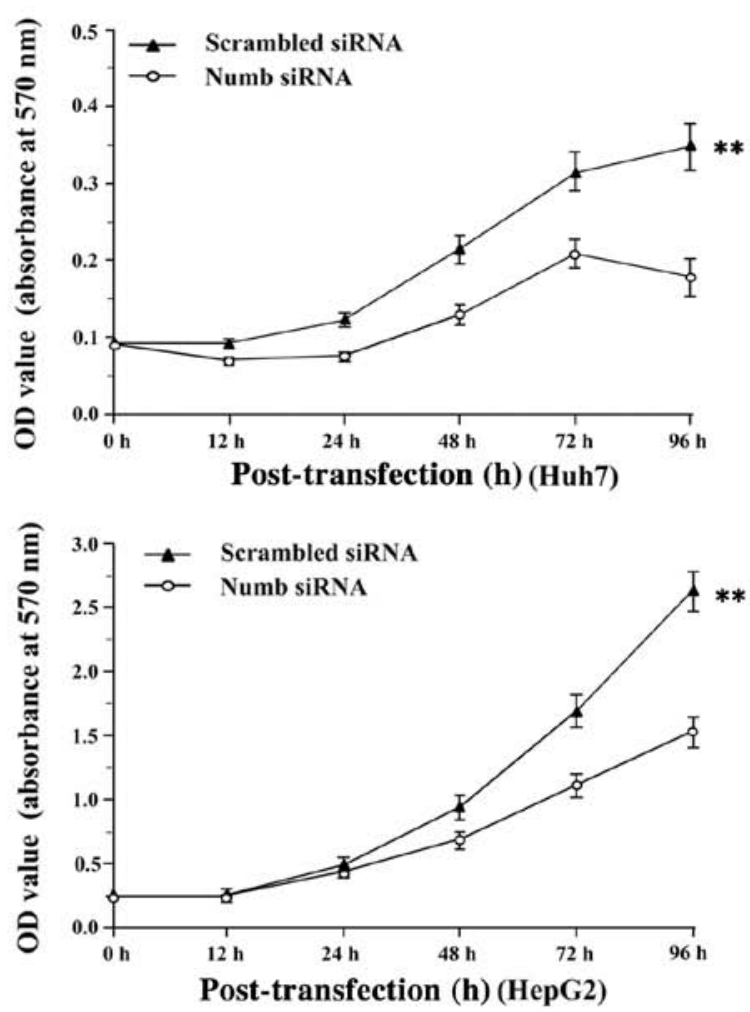

$\mathbf{D}_{\mathbf{a}}$

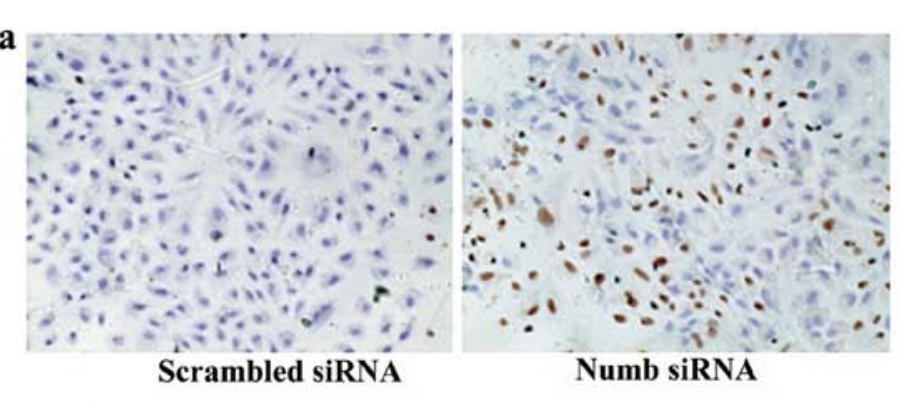

b

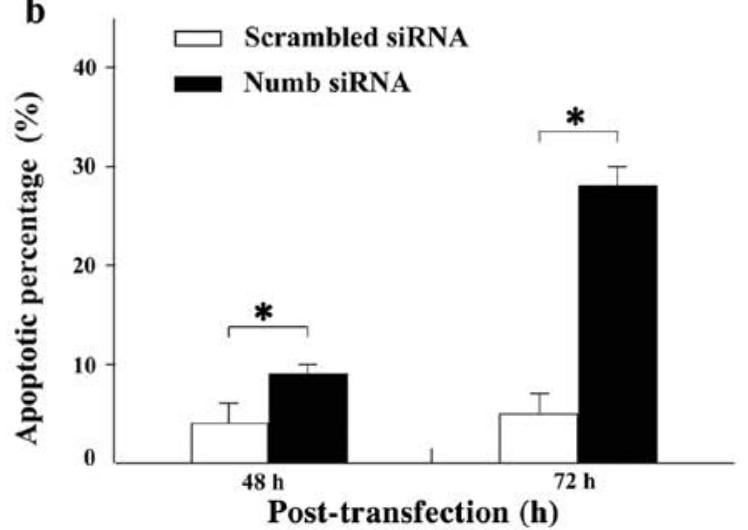

Figure 3. Oncogenetic potential of Numb in hepatocellular carcinomas (HCC). (A) As shown by representative dishes, Numb depletion significantly inhibited the colony formation of Huh7 cells in soft agar culture. Quantitative analyses of colony numbers are shown in the lower panel. Values are the mean \pm standard deviation (SD) of $\geq 3$ independent experiments. (B) MTT assay was performed in Huh7 and HepG2 cells. Growth curves of Numb small interfering RNA (siRNA) cells were compared with the scramble cells, respectively. The results are expressed as mean \pm SD of $\geq 3$ independent experiments. (C) Flow cytometric analysis showing that $N u m b$ siRNA for $24 \mathrm{~h}$ increased the $\mathrm{G}_{0}-\mathrm{G}_{1}$ phase fraction and decreased the $\mathrm{S}$ phase fraction when compared to the scramble treated cultures in Huh7 cells. (D-a) Representative images of TUNEL staining. A larger quantity of apoptotic cells were detected following treatment of Huh7 cells with Numb siRNA in comparison with that of the scramble cells. (D-b) The apoptotic index was compared between Numb siRNA and scramble cells (right panel). ${ }^{* *} \mathrm{P}<0.01,{ }^{*} \mathrm{P}<0.001$.

with hepatitis B virus compared to the normal liver tissue. In addition, Numb was overexpressed in well- and moderately differentiated tumor tissues, which was similar to our previous reports on Vanilloid receptor-1, CB1 and CB2 receptors $(17,19)$. Additionally, downregulation of Numb was associated with aggressive cancer phenotypes, including 

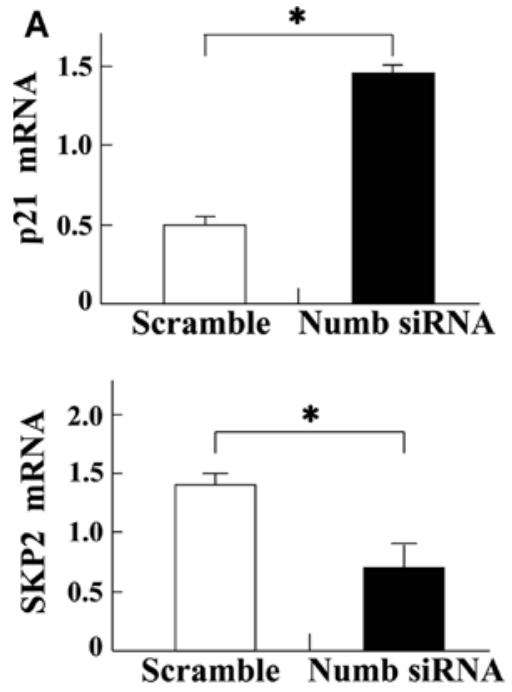
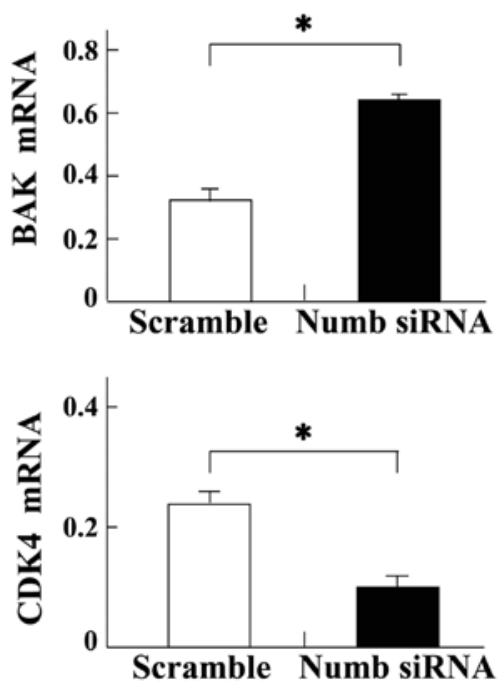

B

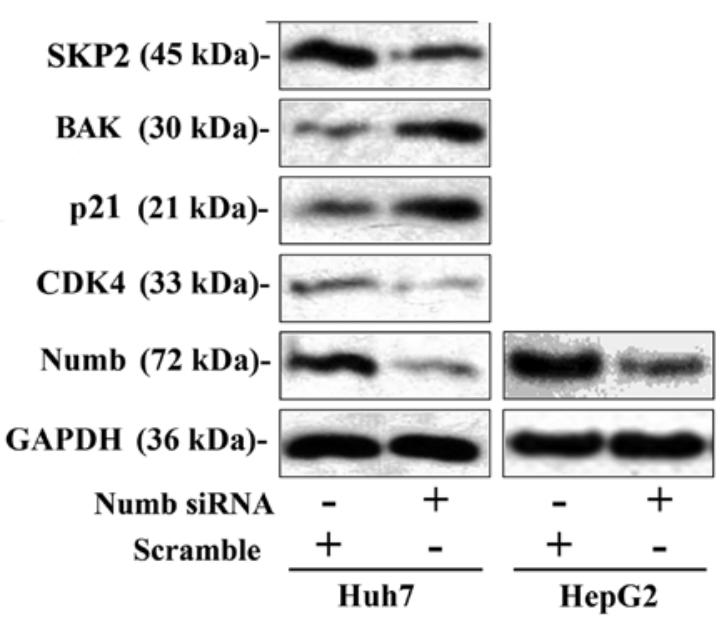

Figure 4. Numb inhibition inducing upregulation of cyclin-dependent kinase inhibitor 1 ( $p 21)$ and Bcl-2 homologous antagonist/killer (BAK), and downregulation of cyclin-dependent protein kinase 4 (CDK4) and S-phase kinase-associated protein 2 (SKP2). (A) Numb small interfering RNA (siRNA) increased p21 and $B A K$ expression, and decreased $C D K 4$ and $S K P 2$ expression at the mRNA level by reverse transcription-quantitative polymerase chain reaction assays. Experiments were performed $24(p 21)$ and $48 \mathrm{~h}(B A K, C D K 4$ and SKP2) after Numb siRNA transfection with Huh7 cells. (B) siRNA against Numb induced p21 and BAK expression, and suppressed CDK4 and SKP2 expression at the protein level. GAPDH served as a loading control. ${ }^{*}<0.05$.

portal vein invasion and dedifferentiated histology (Table III). Univariate and multivariate analyses showed that a low expression of Numb was significantly associated with disease relapse and poor survival of HCC. These data indicate that Numb may serve as an independent predictor for the prognosis of HCC patients.

$N u m b$ is an evolutionary conserved protein that has been indicated in tumorigenesis with roles in controlling stem/progenitor cell development (20). In addition, a number of cellular processes, such as cell adhesion and migration controlled by $N u m b$, are also involved in mammalian tumorigenesis, such as in chronic myelogenous leukaemia, breast cancer, non-small cell lung cancer and salivary gland carcinomas $(13,14,21-24)$. In chronic myelogenous leukaemia, which progress from a slow-growing chronic phase to an aggressive blast crisis phase, high levels of Numb expression were observed in the chronic phase whereas low levels of $N u m b$ expression were observed in the blast crisis phase. In breast cancer, reduced expression of Numb correlating with decreased p53 levels and increased chemo-resistance was found to result in an aggressive tumor phenotype as illustrated by poor prognostic outcome for these patients $(14,25)$. Concordant with these findings, a defect of Numb expression in $\mathrm{HCC}$ was associated with aggressive phenotypes of the tumor and poor outcome of the patients highlighted its involvement in hepatocarcinogenesis.

It has been well documented that DNA methylation of $\mathrm{CpG}$ islands located near gene promoters affects the transcription of specific genes $(26,27)$. Epigenetic inactivation of genes by promotor methylation has been recognized as an important and alternative mechanism in carcinogenesis. In HCC, aberrant promoter methylation of p16 (INK4) is considered a main cause resulting in its function loss $(28,29)$. In the present study, methylated alleles of Numb could be detected in 12/19 (63.2\%) of tumor tissues, indicating the involvement of methylation in hepatocarcinogenesis.
On the basis of those findings above, the role of Numb was further explored in the proliferation of HCC cells. Compared with scramble RNA-treated HCC cells, Numb siRNA silencing resulted in the inhibition of proliferation and colony formation in soft agar, cell-cycle arrest and induction of apoptosis. These results suggest that $N u m b$ has an important role in the proliferative process of HCC cells.

Our previous molecular studies identified that Numb suppression could cause dysregulation of CDK4, SKP2, p21 and BAK, suggesting its roles in several signaling pathways. Numb is involved in p53, Notch and Hedgehog pathways in several tumors (14,30-32). The potential roles of cyclin-cdk complexes, such as CDK and cyclin kinase inhibitor families modulating in the $G_{0}-G_{1}$ phase of the cell cycle, have been addressed in human hepatocarcinogenesis $(33,34)$. Progress has further shown that SKP2, which maintains and preserves the distinct phases during a cell cycle through protein degradation, has emerged in human hepatocarcinogenesis $(35,36)$. The present data showed that $N u m b$ silencing resulted in upregulation of p21 and downregulation of CDK4 and SKP2 in HCC cells, suggesting involvement of $N u m b$ in the $\mathrm{G}_{1}-\mathrm{S}$ phase of a cell cycle. In addition, BAK is a well-known cell death initiator in the apoptotic signaling cascade, and its roles in hepatocarcinogensis or for HCC treatment have also been documented $(37,38)$. Different agents induce apoptosis in HCC cells by stimulating $B A K$ expression, suggesting its pro-apoptotic effect $(39,40)$. The present findings that upregulation of $B A K$ was caused by $N u m b$ silencing highlights the role of Numb in apoptosis induction. Interactions among these molecules as targeted by Numb warrant further detailed investigation.

Based on the findings of the present study, it can be concluded that downregulation of Numb may be a predictor of HCC prognosis, and Numb has an important role in the proliferation of HCC cells in vitro via interaction with CDK4, p21, SKP2 and BAK. Numb may be a potential therapeutic target for HCC patients. 


\section{References}

1. Torre LA, Bray F, Siegel RL, Ferlay J, Lortet-Tieulent J and Jemal A: Global cancer statistics, 2012. CA Cancer J Clin 65: 87-108, 2015

2. Xu X, Yamamoto H, Liu G, Ito Y, Ngan CY, Kondo M, Nagano H, Dono K, Sekimoto M and Monden M: CDC25A inhibition suppresses the growth and invasion of human hepatocellular carcinoma cells. Int J Mol Med 21: 145-152, 2008

3. Martínez-López N, Varela-Rey M, Fernández-Ramos D, Woodhoo A, Vázquez-Chantada M,Embade N,Espinosa-Hevia L, Bustamante FJ, Parada LA, Rodriguez MS, et al: Activation of LKB1-Akt pathway independent of phosphoinositide 3-kinase plays a critical role in the proliferation of hepatocellular carcinoma from nonalcoholic steatohepatitis. Hepatology 52: $1621-1631,2010$

4. Xu J, Yun X, Jiang J, Wei Y, Wu Y, Zhang W, Liu Y, Wang W, Wen $Y$ and $G u J$ : Hepatitis B virus $X$ protein blunts senescence-like growth arrest of human hepatocellular carcinoma by reducing Notch1 cleavage. Hepatology 52: 142-154, 2010.

5. Rhyu MS, Jan LY and Jan YN: Asymmetric distribution of numb protein during division of the sensory organ precursor cell confers distinct fates to daughter cells. Cell 76: 477-491, 1994

6. Spana EP, Kopczynski C, Goodman CS and Doe CQ: Asymmetric localization of numb autonomously determines sibling neuron identity in the Drosophila CNS. Development 121: 3489-3494, 1995.

7. Vervoort M, Dambly-Chaudière $\mathrm{C}$ and Ghysen A: Cell fate determination in Drosophila. Curr Opin Neurobiol 7: 21-28, 1997.

8. Park M, Yaich LE and Bodmer R: Mesodermal cell fate decisions in Drosophila are under the control of the lineage genes numb, Notch, and sanpodo. Mech Dev 75: 117-126, 1998.

9. Spana EP and Doe CQ: Numb antagonizes Notch signaling to specify sibling neuron cell fates. Neuron 17: 21-26, 1996.

10. Guo M, Jan LY and Jan YN: Control of daughter cell fates during asymmetric division: Interaction of Numb and Notch. Neuron 17: 27-41, 1996.

11. Chien CT, Wang S, Rothenberg M, Jan LY and Jan YN: Numb-associated kinase interacts with the phosphotyrosine binding domain of Numb and antagonizes the function of Numb in vivo. Mol Cell Biol 18: 598-607, 1998.

12. Bric A, Miething C, Bialucha CU, Scuoppo C, Zender L, Krasnitz A, Xuan Z, Zuber J, Wigler M, Hicks J, et al: Functional identification of tumor-suppressor genes through an in vivo RNA interference screen in a mouse lymphoma model. Cancer Cell 16: 324-335, 2009

13. Pece S, Serresi M, Santolini E, Capra M, Hulleman E, Galimberti V,Zurrida S, Maisonneuve P, Viale G and Di Fiore PP: Loss of negative regulation by Numb over Notch is relevant to human breast carcinogenesis. J Cell Biol 167: 215-221, 2004

14. Colaluca IN, Tosoni D, Nuciforo P, Senic-Matuglia F, Galimberti V, Viale G, Pece S and Di Fiore PP: NUMB controls p53 tumour suppressor activity. Nature 451: 76-80, 2008.

15. Liu G, Xie C, Sun F, Xu X, Yang Y, Zhang T, Deng Y, Wang D, Huang Z, Yang L, et al: Clinical significance of transient receptor potential vanilloid 2 expression in human hepatocellular carcinoma. Cancer Genet Cytogenet 197: 54-59, 2010

16. Xie C, Liu G, Liu J, Huang Z, Wang F, Lei X, Wu X, Huang S, Zhong D and Xu X: Anti-proliferative effects of anandamide in human hepatocellular carcinoma cells. Oncol Lett 4: 403-407, 2012.

17. Miao X, Liu G, Xu X, Xie C, Sun F, Yang Y, Zhang T, Hua S, Fan W, Li Q, et al: High expression of vanilloid receptor-1 is associated with better prognosis of patients with hepatocellular carcinoma. Cancer Genet Cytogenet 186: 25-32, 2008.

18. Fu L, Qin YR, Xie D, Hu L, Kwong DL, Srivastava G, Tsao SW and Guan XY: Characterization of a novel tumor-suppressor gene PLC delta 1 at 3 p22 in esophageal squamous cell carcinoma. Cancer Res 67: 10720-10726, 2007.

19. Xu X, Liu Y, Huang S, Liu G, Xie C, Zhou J, Fan W, Li Q, Wang Q, Zhong D, et al: Overexpression of cannabinoid receptors $\mathrm{CB} 1$ and CB2 correlates with improved prognosis of patients with hepatocellular carcinoma. Cancer Genet Cytogenet 171: 31-38, 2006.

20. Neumüller RA and Knoblich JA: Dividing cellular asymmetry: Asymmetric cell division and its implications for stem cells and cancer. Genes Dev 23: 2675-2699, 2009.
21. Zhao C, Chen A, Jamieson CH, Fereshteh M, Abrahamsson A, Blum J, Kwon HY, Kim J, Chute JP, Rizzieri D, et al: Hedgehog signalling is essential for maintenance of cancer stem cells in myeloid leukaemia. Nature 458: 776-779, 2009.

22. Ito T, Kwon HY, Zimdahl B, Congdon KL, Blum J, Lento WE, Zhao C, Lagoo A, Gerrard G, Foroni L, et al: Regulation of myeloid leukaemia by the cell-fate determinant Musashi. Nature 466: 765-768, 2010.

23. Westhoff B, Colaluca IN, D'Ario G, Donzelli M, Tosoni D, Volorio S, Pelosi G, Spaggiari L, Mazzarol G, Viale G, et al: Alterations of the Notch pathway in lung cancer. Proc Natl Acad Sci USA 106: 22293-22298, 2009.

24. Maiorano E, Favia G, Pece S, Resta L, Maisonneuve P, Di Fiore PP, Capodiferro S, Urbani U and Viale G: Prognostic implications of NUMB immunoreactivity in salivary gland carcinomas. Int J Immunopathol Pharmacol 20: 779-789, 2007.

25. Rennstam K, McMichael N, Berglund P, Honeth G, Hegardt C, Rydén L, Luts L, Bendahl PO and Hedenfalk I: Numb protein expression correlates with a basal-like phenotype and cancer stem cell markers in primary breast cancer. Breast Cancer Res Treat 122: 315-324, 2010.

26. Sakai T, Toguchida J, Ohtani N, Yandell DW, Rapaport JM and Dryja TP: Allele-specific hypermethylation of the retinoblastoma tumor-suppressor gene. Am J Hum Genet 48: 880-888, 1991.

27. Merlo A, Herman JG, Mao L, Lee DJ, Gabrielson E, Burger PC, Baylin SB and Sidransky D: $5^{\prime} \mathrm{CpG}$ island methylation is associated with transcriptional silencing of the tumour suppressor p16/CDKN2/MTS1 in human cancers. Nat Med 1: 686-692, 1995.

28. Matsuda Y, Ichida T, Matsuzawa J, Sugimura K and Asakura H: p16(INK4) is inactivated by extensive CpG methylation in human hepatocellular carcinoma. Gastroenterology 116: 394-400, 1999.

29. Li X, Hui AM, Sun L, Hasegawa K, Torzilli G, Minagawa M, Takayama T and Makuuchi M: p16INK4A hypermethylation is associated with hepatitis virus infection, age, and gender in hepatocellular carcinoma. Clin Cancer Res 10: 7484-7489, 2004.

30. Chapman G, Liu L, Sahlgren C, Dahlqvist C and Lendahl U: High levels of Notch signaling down-regulate Numb and Numblike. J Cell Biol 175: 535-540, 2006

31. McGill MA, Dho SE, Weinmaster G and McGlade CJ: Numb regulates post-endocytic trafficking and degradation of Notch1. J Biol Chem 284: 26427-26438, 2009.

32. Di Marcotullio L, Ferretti E, Greco A, De Smaele E, Po A, Sico MA, Alimandi M, Giannini G, Maroder M, Screpanti I, et al: Numb is a suppressor of Hedgehog signalling and targets Gli1 for Itch-dependent ubiquitination. Nat Cell Biol 8: 1415-1423, 2006.

33. Greenbaum LE: Cell cycle regulation and hepatocarcinogenesis. Cancer Biol Ther 3: 1200-1207, 2004

34. Hui AM, Makuuchi M and Li X: Cell cycle regulators and human hepatocarcinogenesis. Hepatogastroenterology 45: 1635-1642, 1998.

35. Calvisi DF, Ladu S, Pinna F, Frau M, Tomasi ML, Sini M, Simile MM, Bonelli P, Muroni MR, Seddaiu MA, et al: SKP2 and CKS1 promote degradation of cell cycle regulators and are associated with hepatocellular carcinoma prognosis. Gastroenterology 137: 1816-26.e10, 2009.

36. Ho C, Wang C, Mattu S, Destefanis G, Ladu S, Delogu S, Armbruster J, Fan L, Lee SA, Jiang L, et al: AKT (v-akt murine thymoma viral oncogene homolog 1) and N-Ras (neuroblastoma ras viral oncogene homolog) coactivation in the mouse liver promotes rapid carcinogenesis by way of mTOR (mammalian target of rapamycin complex 1), FOXM1 (forkhead box M1)/SKP2, and c-Myc pathways. Hepatology 55: 833-845, 2012.

37. Cory S and Adams JM: The Bcl2 family: Regulators of the cellular life-or-death switch. Nat Rev Cancer 2: 647-656, 2002.

38. Griffiths GJ, Dubrez L, Morgan CP, Jones NA, Whitehouse J, Corfe BM, Dive C and Hickman JA: Cell damage-induced conformational changes of the pro-apoptotic protein Bak in vivo precede the onset of apoptosis. J Cell Biol 144: 903-914, 1999.

39. Hu R, Zhai Q, Liu W and Liu X: An insight into the mechanism of cytotoxicity of ricin to hepatoma cell: Roles of Bcl-2 family proteins, caspases, $\mathrm{Ca}(2+)$-dependent proteases and protein kinase C. J Cell Biochem 81: 583-593, 2001.

40. Wang QF, Chen JC, Hsieh SJ, Cheng CC and Hsu SL: Regulation of Bcl-2 family molecules and activation of caspase cascade involved in gypenosides-induced apoptosis in human hepatoma cells. Cancer Lett 183: 169-178, 2002. 